\title{
EL IMPACTO DE LA CRISIS ECONÓMICA (2008-2013) SOBRE EL EMPRENDIMIENTO EN ESPAÑA: UN ANÁLISIS A PARTIR DE LOS DATOS DEL GLOBAL ENTREPRENEURSHIP MONITOR
}

\author{
Autor: Alfonso Jesús Torres Marin ${ }^{1}$ \\ Facultad de Ciencias Jurídicas y Sociales \\ Departamento de Economía Aplicada I \\ Universidad Rey Juan Carlos
}

\section{Resumen}

En este trabajo se analiza el impacto de la crisis económica acontecida en España entre 2008 y 2013 sobre el emprendimiento. Se han utilizado principalmente los datos publicados en los informes de Global Entrepreneurship Monitor España correspondientes al periodo 2005-2015 para explicar el efecto de la negativa coyuntura económica sobre una serie de aspectos fundamentales entre los que se encuentran: (a) los valores, percepciones y aptitudes emprendedoras de la población, (b) la actividad emprendedora y sus características -en términos de

1.alfonso.torres@urjc.es

icade. Revista cuatrimestral de las Facultades de Derecho y Ciencias Económicas y Empresariales, $n^{\circ} 99$ septiembre-diciembre 2016, ISSN: 1889-7045 
perfil sociodemográfico del emprendedor y sus aspiraciones- y (c) el contexto en el que se desarrolla el proceso emprendedor.

Palabras clave: emprendedor; crisis económica; Global Entrepreneurship Monitor.

The impact of the economic crisis (2008-2013) on entrepreneurship in Spain: an analysis of data from the Global Entrepreneurship Monitor

\begin{abstract}
This paper analyzes the impact of the economic crisis occurred in Spain between 2008 and 2013 on entrepreneurship. It uses data published in the Global Entrepreneurship Monitor Spain reports for the period 2005-2015 to explain the effect of the negative economic situation on a number of key issues among which are: (a) the values, perceptions and entrepreneurial skills of the population, (b) entrepreneurial activity and its characteristics -in terms of socio-demographic profile of the entrepreneurs and their aspirations- and (c) the context in which the entrepreneurial process unfolds.
\end{abstract}

Key words: entrepreneur; economic crisis; Global Entrepreneurship Monitor.

Recibido: 19/09/2016

Aceptado: 24/11/2016

\title{
1. INTRODUCCIÓN
}

Distintos estudios señalan que el principal detonante de un proceso emprendedor está relacionado con un estado de alerta a partir del cual surge el reconocimiento, descubrimiento o la generación de una idea de negocio que da respuesta a una necesidad o incluso crea una necesidad en el mercado, lo que aportará un valor económico o social².

Dicho estado de alerta suele venir condicionado por las características del individuo (habilidades, conocimientos, miedo al posible fracaso, modelos de referencia disponibles) y contextuales (nivel de vida, imagen que la sociedad tiene del emprendedor etc.). Las condiciones de los individuos y el contexto van variando y combinándose en el tiempo transformándose en un conjunto de valores,

${ }^{2}$ Véase Ardichvili y Cardozo (2000), Ardichvili et al. (2003) y Sarasvathy et al. (2010). 
percepciones y aptitudes de la sociedad acerca de la actividad emprendedora que acontece en su entorno.

Cambios sustanciales en la coyuntura económica pueden afectar al emprendimiento en un país en diversas dimensiones. De un lado altera los valores, percepciones y aptitudes emprendedoras de la población. En segundo lugar, influye sobre la actividad emprendedora y sus características, tanto en lo que se refiere al perfil sociodemográfico del emprendedor como a las aspiraciones asociadas a dicha actividad. Por último, el propio contexto en el que se desarrolla el proceso emprendedor podría verse modificado.

En este trabajo se analiza el impacto de la crisis económica acontecida en España entre 2008 y 2013 sobre el emprendimiento. Se han utilizado principalmente los datos publicados en los informes de Global Entrepreneurship Monitor España (GEM) correspondientes al periodo 2005-2015 para explicar el efecto de la recesión sobre las tres dimensiones expuestas en el párrafo anterior. No se trata de un trabajo analítico, sino que pretende más bien realizar una explotación inicial de los datos del GEM.

El presente artículo se ha estructurado en 4 bloques: en primer lugar, se realiza una breve descripción del Global Entrepreneurship Monitor, su metodología, y las particularidades en el caso español; en segundo lugar, se revisa la evolución de las principales macro magnitudes económicas en el periodo 2005-2015 para ganar una cierta perspectiva en la comprensión de la profundidad de la recesión; en tercer lugar se analiza de forma detallada el impacto de la crisis económica sobre el emprendimiento en España. El contenido de este apartado se estructura de modo que se cubre el impacto de la recesión económica sobre los valores, percepciones y aptitudes emprendedoras de la población, la actividad emprendedora, el perfil sociodemográfico del emprendedor, las aspiraciones que se derivan de su actividad, y los cambios en el entorno emprendedor. En el último epígrafe se presentan, a modo de resumen, las principales conclusiones obtenidas del trabajo realizado.

\section{EL GLOBAL ENTREPRENEURSHIP MONITOR ESPAÑA}

El Global Entrepreneurship Monitor (GEM) es un observatorio internacional que analiza el fenómeno emprendedor. El proyecto se realiza anualmente en más de 60 países con una metodología homologable, lo que permite resultados comparables a nivel mundial. En cuanto a su Metodología, el GEM se basa en tres fuentes de información fundamentales: en primer lugar, se realiza una encuesta dirigida a la población de edades comprendidas entre 18 y 64 años. Esta sirve para obtener los principales indicadores de actividad emprendedora; en segundo término, se encuesta a expertos en el entorno para emprender. El objetivo es valorar el estado de las variables que influyen en el proceso emprendedor y que pueden 
condicionar su magnitud y características. Cada país selecciona su propio grupo de expertos en financiación, políticas gubernamentales, programas públicos, educación, transferencia de I+D, infraestructura comercial y física, apertura del mercado interno y normas sociales y culturales, que son entrevistados a través de un cuestionario diseñado ex profeso; por último, se emplean fuentes secundarias de cada país sobre desarrollo económico, demografía, mercado laboral, innovación, competitividad, etc.

En España se realizaron más de 24.000 encuestas a población comprendida entre 18 y 64 años y a más de 36 expertos cualificados en la edición 2015. Estas cifras se han mantenido en unos niveles similares para el periodo de análisis propuesto en este documento (2005-2015). Ello dota a los resultados obtenidos en estos estudios de un elevado grado confianza. El estudio se estructura en dos apartados en los que se analizan el fenómeno y el entorno emprendedor. En ambos casos se presentan los resultados a nivel nacional y desglosados por comunidades autónomas, así como diversos benchmarking internacionales.

El emprendimiento es entendido como un proceso que, como se muestra en la Tabla 1, comienza con la generación de una idea (emprendimiento potencial), continúa con su puesta en marcha y lanzamiento al mercado (emprendimiento naciente), entra en una fase de consolidación (emprendimiento nuevo) y llega a la fase consolidada si sobrevive durante más de tres años y medio. En cualquier momento de este proceso se puede producir el abandono de la empresa por parte de los promotores dando lugar al cierre definitivo o al traspaso de la misma.

\section{Tabla 1. El proceso emprendedor según el proyecto GEM}

\begin{tabular}{|l|}
\hline \multicolumn{1}{|c|}{ TEA (Total Entrepreneurial Activity) } \\
\hline \multicolumn{1}{|c|}{ Emprendimiento Potencial } \\
\hline $\begin{array}{l}\text { Parte de la población de } 18 \text { a } 64 \text { años que ha expresado su deseo de emprender en los próximos } \\
3 \text { años. }\end{array}$ \\
\hline \multicolumn{1}{|c|}{ Emprendimiento Naciente } \\
\hline $\begin{array}{l}\text { Iniciativas que se hallan en fase de despegue: no han pagado salarios por más de } 3 \text { meses, sobre } \\
\text { la población de } 18 \text { a } 64 \text { años. }\end{array}$ \\
\hline $\begin{array}{l}\text { Iniciativas que se hallan en fase de consolidación: entre } 3 \text { y } 42 \text { meses de actividad económica, } \\
\text { sobre la población de } 18 \text { a } 64 \text { años. }\end{array}$ \\
\hline $\begin{array}{l}\text { Empresas que han superado las fases anteriores y llevan más de } 42 \text { meses operando en el } \\
\text { mercado, sobre la población de } 18 \text { a } 64 \text { años. }\end{array}$ \\
\hline
\end{tabular}

Fuente: Global Entrepreneurship Monitor España (2015). 


\section{LA CRISIS ECONÓMICA EN ESPAÑA (2008-2013)}

Se ha escrito mucho sobre el origen y las consecuencias de la crisis económica que se ha vivido en España entre finales del año 2008 y 2013. No obstante, no es el objetivo de este trabajo reparar en la misma de forma detallada, sino, como se indicó en la introducción, analizar el impacto que ésta ha tenido sobre el emprendimiento a distintos niveles. Por ello este documento se limita a hacer una breve descripción de la evolución de las principales macro magnitudes en el periodo 2008-2013 con el fin de facilitar al lector la comprensión de su profundidad.

En el periodo comprendido entre diciembre de 2008 y diciembre del 2013 el PIB real español disminuyó en un 7,6\%. Especialmente duros resultaron los años 2009 y 2012 con decrecimientos interanuales del $-3,6 \%$ y $-2,6 \%$ respectivamente. El PIB real per cápita se redujo un 7,3\%. De nuevo 2009 y 2012 con caídas respectivas del $-4,1 \%$ y $-1,9 \%$ resultaron los años más difíciles. La tasa de desempleo se incrementó desde el 13,8\% al 25,7\%. No obstante, hay que recordar que el año 2007 finalizó con una tasa de desempleo del 8,6\% y que los últimos meses de 2008 ya reflejaban claramente nuestra entrada en la crisis. La deuda pública pasó de representar el 39,4\% del PIB al 93,7\% debido a los elevados déficits públicos generados. El saldo de la balanza por cuenta corriente pasó de un déficit del $-9,3 \%$ del PIB en 2008 a un superávit 1,4\%, reflejando un notable esfuerzo exportador de nuestras empresas.

No resulta difícil imaginar que esta coyuntura ha supuesto un cambio muy importante en el escenario económico al que se enfrentaban los consumidores, las empresas y los demás agentes económicos, que en términos globales vieron mermadas sus oportunidades laborales y empresariales, así como su renta, sus beneficios, y las ayudas públicas, al tiempo que se incrementaban las dificultades para conseguir financiación bancaria debido a los problemas específicos que atravesaba el sector financiero.

Durante los años 2014 y 2015 las magnitudes anteriores han evolucionado en términos positivos. Así, tanto el PIB real total como en términos per cápita ha crecido, la tasa de desempleo se ha reducido, la deuda pública ha moderado su ritmo de crecimiento y el superávit por cuenta corriente se ha mantenido. Ello nos sitúa en un escenario claramente mejor que el observado entre 2008 y 2013, lo cual debería afectar positivamente al emprendimiento en España. La Tabla 2, que se presenta a continuación, recoge la evolución de las variables macroeconómicas descritas en este apartado. 
Tabla 2. Evolución de los principales agregados económicos en España. Periodo 2005-2015

\begin{tabular}{|c|c|c|c|c|c|}
\hline Año & $\begin{array}{c}\% \text { Variación } \\
\text { PIB real }\end{array}$ & $\begin{array}{c}\% \text { Variación } \\
\text { PIB real } \\
\text { percapita }\end{array}$ & $\begin{array}{c}\text { Tasa de } \\
\text { desempleo } \\
(\%)\end{array}$ & $\begin{array}{c}\text { Deuda } \\
\text { Pública } \\
(\% \text { PIB) }\end{array}$ & $\begin{array}{c}\text { Saldo Balanza } \\
\text { Pagos Cuenta } \\
\text { Corriente } \\
(\% \text { PIB) }\end{array}$ \\
\hline 2015 & $3,2 \%$ & $2,2 \%$ & $20,9 \%$ & $99,2 \%$ & $1,5 \%$ \\
\hline 2014 & $1,4 \%$ & $1,2 \%$ & $23,7 \%$ & $99,3 \%$ & $0,8 \%$ \\
\hline 2013 & $-1,7 \%$ & $-0,2 \%$ & $25,7 \%$ & $93,7 \%$ & $1,4 \%$ \\
\hline 2012 & $-2,6 \%$ & $-1,9 \%$ & $25,8 \%$ & $85,4 \%$ & $-0,3 \%$ \\
\hline 2011 & $-1,0 \%$ & $-0,9 \%$ & $22,6 \%$ & $69,5 \%$ & $-3,2 \%$ \\
\hline 2010 & $0,0 \%$ & $-0,2 \%$ & $20,1 \%$ & $60,1 \%$ & $-3,9 \%$ \\
\hline 2009 & $-3,6 \%$ & $-4,1 \%$ & $16,7 \%$ & $52,7 \%$ & $-4,3 \%$ \\
\hline 2008 & $1,1 \%$ & $1,6 \%$ & $13,8 \%$ & $39,4 \%$ & $-9,3 \%$ \\
\hline 2007 & $3,8 \%$ & $5,2 \%$ & $8,6 \%$ & $35,5 \%$ & $-10,1 \%$ \\
\hline 2006 & $4,2 \%$ & $6,6 \%$ & $8,3 \%$ & $38,9 \%$ & $-8,7 \%$ \\
\hline 2005 & $3,7 \%$ & $6,0 \%$ & $8,7 \%$ & $42,3 \%$ & $-7,4 \%$ \\
\hline
\end{tabular}

Fuente: INE y Banco de España.

\section{EL IMPACTO DE LA CRISIS ECONÓMICA SOBRE EL EMPRENDI- MIENTO EN ESPAÑA}

A continuación, se analiza el impacto que tuvo la recesión acontecida en España entre 2008 y 2013 sobre el emprendimiento. Se ha considerado un periodo de tiempo más amplio (2005-2015), para facilitar las comparaciones entre los periodos de expansión y de crisis económica.

El contenido de este apartado se estructura en cinco bloques en los que se aborda el efecto de la crisis sobre las dimensiones del fenómeno emprendedor que se indicaron en la introducción y que ahora se recuerdan nuevamente: (1) los valores percepciones y aptitudes emprendedoras de la población, (2) la actividad emprendedora, (3) el perfil del emprendedor, (4) las aspiraciones de la actividad emprendedora, y (5) el entorno emprendedor.

\subsection{Los valores, percepciones y aptitudes emprendedoras de la población}

Una de las consecuencias derivadas de la crisis económica fue la caída en las oportunidades emprendedoras percibidas, que afectó tanto al conjunto de la población adulta activa (de 18 a 64 años) como a la población involucrada en el proceso emprendedor (aquellas personas que han iniciado un negocio o que son propietarias de negocios establecidos). Como se observa en el Gráfico 1, durante 
el periodo previo a la crisis económica (2005-2008) un 26\% de la población adulta activa percibía oportunidades para emprender en los seis meses siguientes. Dicho porcentaje se redujo hasta el 16\% durante la recesión (2009-2013), para volver a recuperarse en el periodo 2014-2015, hasta alcanzar niveles ligeramente inferiores a los existentes con anterioridad. La población involucrada en iniciativas emprendedoras percibe más oportunidades que la media. No obstante, la crisis ha tenido los mismos efectos que los señalados para el conjunto de la población. La recesión redujo las oportunidades percibidas para emprender de este colectivo desde el $38,9 \%$ en el periodo 2005-2008 hasta el 23,2\% entre 2009-2013 para recuperarse hasta alcanzar niveles similares a los previos a la crisis, en el bienio 2014-2015.

\section{Gráfico 1. Evolución de la percepción de las oportunidades de emprender en los próximos seis meses en España. Periodo 2005-2015}

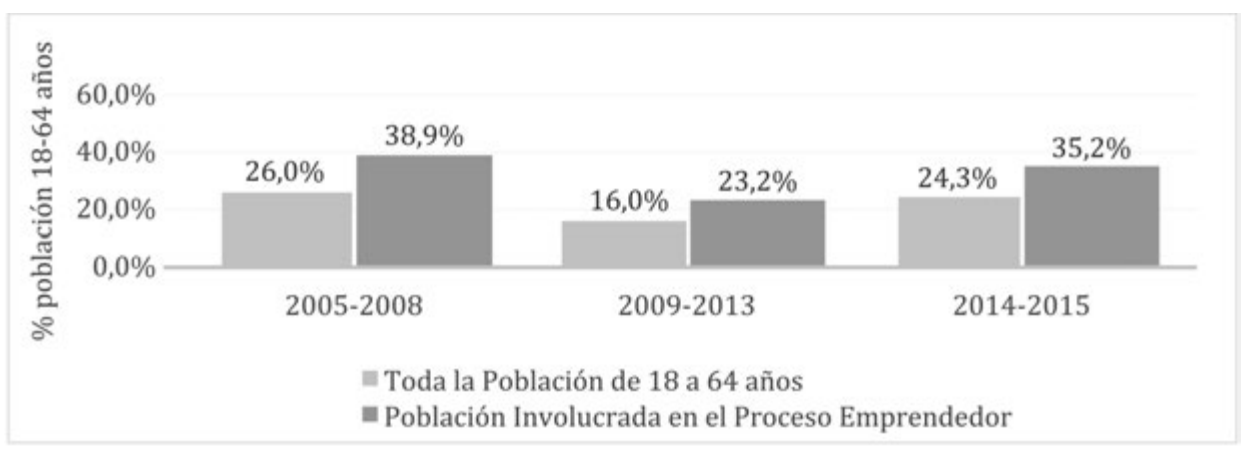

Fuente: elaboración propia a partir de los datos del GEM.

Otro aspecto importante a analizar es el capital humano que tienen los individuos para enfrentarse a las dificultades propias de cada una de las fases del proceso emprendedor (identificación, creación, crecimiento, consolidación, abandono). Este capital humano incluye los conocimientos (financieros, de mercado, etc.), las habilidades (gestión, negociación, etc.) y las experiencias previas (laboral, inversora, emprendedora) que son fundamentales para llevar a buen puerto el proyecto emprendedor. El porcentaje de la población adulta activa que indicó disponer del capital humano (conocimientos, habilidades y experiencia) adecuado que se requiere como emprendedor se incrementó pasando del 48,1\% de la población (2005-2008) al 50,1\% (2009-2013). Durante el periodo 2014-15, una vez finalizada la recesión, dicho porcentaje se redujo nuevamente, hasta el 46,7\%. Se podría interpretar este resultado como el fruto de un esfuerzo para incrementar el nivel de formación de la población en los momentos de crisis para poder enfrentarse con mayores probabilidades de éxito a las dificultades de la coyuntura. La población involucrada en el proceso emprendedor que manifestó disponer de 
un nivel de formación adecuado para emprender se mantuvo estable a lo largo de todo el periodo en unas tasas que oscilaron entre el $84 \%$ y el $86 \%$.

El riesgo asumido por el individuo en las distintas etapas del proceso emprendedor es un factor relevante a la hora de emprender. Cuando una persona se enfrenta a opciones con distintos niveles de incertidumbre sobre sus costes-beneficios tiende a seleccionar aquella que le permite lograr sus expectativas, asumiendo que debe aceptar ciertos riesgos. Aquellos que evitan situaciones de riesgo suelen estar influenciados por el miedo a fracasar, por lo que emprender les resulta menos atractivo y prefieren otras alternativas que les generen menos incertidumbre. La percepción del miedo al fracaso a la hora de emprender se ha visto reducido en la última década de forma muy intensa en la población involucrada en el proceso emprendedor y de manera muy ligera en las personas no involucradas en el mismo. Como muestra el Gráfico 2, en el año 2008 el miedo al fracaso representaba un obstáculo a la hora de emprender para el $62 \%$ de los emprendedores y cinco años después tan solo era mencionado por el 35,1\%. Ello evidencia que las personas que emprenden son más conscientes de los riesgos y dificultades a los que pueden enfrentarse a lo largo del proceso, por lo cual, estarían dispuestos a asumir un cierto margen de pérdida.

\section{Gráfico 2. Evolución de la percepción del miedo al fracaso como un obstáculo para emprender en España. Periodo 2005-2015}

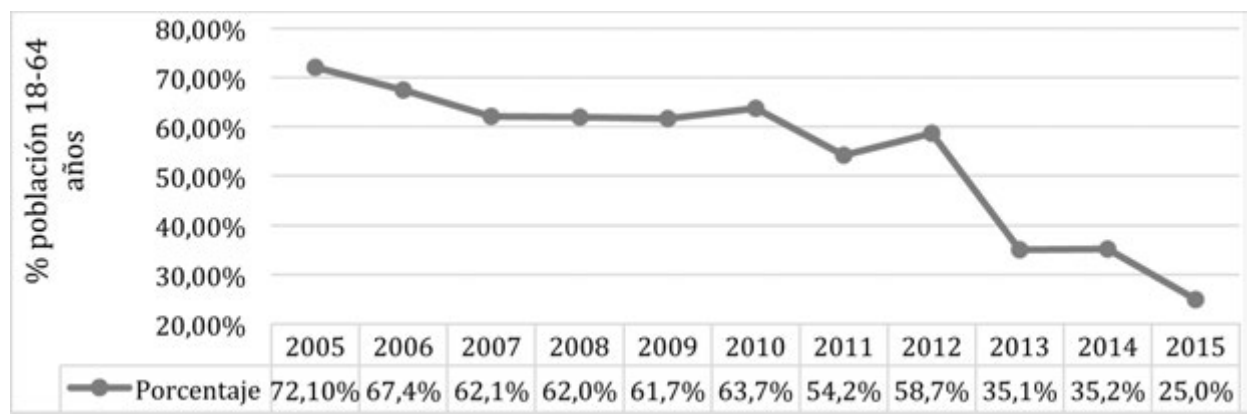

Fuente: elaboración propia a partir de los datos del GEM.

También es interesante analizar si las personas reconocen la existencia de emprendedores en su zona de residencia ya que esto puede servirles como modelo de referencia e imitar al emprendedor ("si el puede, yo también"), o para crear una red de colaboración para emprender. La crisis económica española ha supuesto una reducción de la población que percibe modelos de referencia en otros emprendedores. Ello ha conllevado una reducción del posible efecto imitación y de creación de redes de emprendedores, actuando como un desincentivo al emprendimiento. Durante el periodo de recesión el porcentaje de población que conocía 
a personas que habían emprendido se redujo desde el 34,7\% (2005-2008) hasta el 31,1\% (2009-2013), recuperándose de nuevo en el periodo inmediatamente posterior hasta sus niveles iniciales.

Los valores y comportamientos de los españoles descritos en los párrafos anteriores, suelen estar condicionados por la cultura y las características de la población. Por ello es fundamental conocer aquellos factores socioculturales que pueden influir en el comportamiento emprendedor; como por ejemplo si ser emprendedor es una buena opción profesional o como se percibe el estatus socio económico del emprendedor. En lo que concierne a la opinión de las personas sobre si ser emprendedor es una buena opción profesional se observa una clara tendencia a la baja en el período 2005-2015 en el que se ha pasado de un 71,4\% de la población que estaban de acuerdo con esta afirmación a un 53,2\%. Esta tendencia también se ha mantenido entre 2008 y 2013 (en el que se pasó del 68,2\% al $54,3 \%$ ) y evidencia que ser emprendedor está cada vez menos valorado en la sociedad española, independientemente de la crisis económica.

Si se analiza lo acontecido en el periodo 2005-2015, cada vez son menos los españoles que perciben que emprender brinda un mayor estatus social y económico -véase Gráfico 3-. Esto implica que la sociedad española tiende a valorar cada vez menos el éxito de los emprendedores. Quizá debido al coste beneficio o porque se considera como una profesión de mayor riesgo.

\section{Gráfico 3. Evolución de la opinión de que emprender brinda estatus social y económico en España. Periodo 2005-2015}

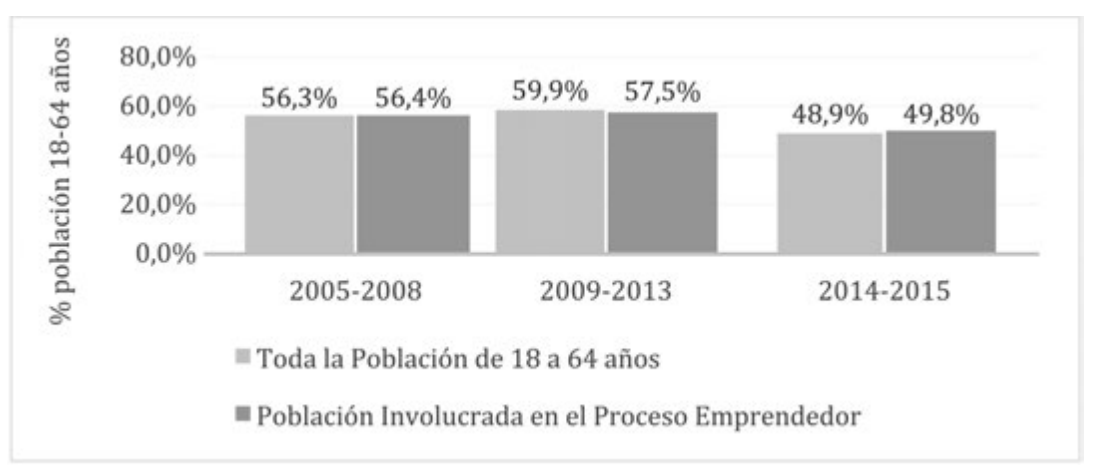

Fuente: elaboración propia a partir de los datos del GEM.

Curiosamente, durante el periodo de crisis económica esta tendencia se rompió y como se observa en el Gráfico 3, el porcentaje de la población (tanto involucrada, como general) que percibió que emprender brinda un mayor estatus económico se vio incrementada, para caer con fuerza al finalizar la recesión. 


\subsection{La actividad emprendedora}

La actividad de emprender no es un evento, sino un proceso que se materializa de diversas maneras, siendo la creación de empresas una de ellas. Este proceso comprende la identificación de nuevas oportunidades de negocio en el mercado, así como su evaluación y explotación ${ }^{3}$. Por ello es fundamental analizar este proceso identificando a las personas emprendedoras que se encuentran en distintas etapas del mismo y diferenciando entre emprendedores potenciales, nacientes y nuevos (véase Tabla 1).

Se denomina Tasa de Actividad Emprendedora o TEA al porcentaje de empresarios nacientes más el porcentaje de emprendedores nuevos (aquellos con actividad económica durante menos de 42 meses).

Durante los cinco años de recesión el porcentaje de emprendedores potenciales en España se incrementó desde el 6,6\% de la población adulta activa, hasta el $8,6 \%$. Posiblemente ello tenga que ver con que la crisis económica predispuso a que más personas se planteasen la posibilidad de emprender como una alternativa a las dificultades que estaban teniendo lugar en el mercado laboral (emprendimiento por necesidad). Sin embargo la Tasa de actividad emprendedora (TEA) se vió reducida durante el mismo periodo desde el 6,9\% hasta el 5,2\%. El TEA mínimo de toda la década se alcanzó en el año 2010 (4,3\%). La salida de la crisis ha supuesto una cierta recuperación de la tasa de actividad emprendedora -aún lejos de su nivel pre crisis- y una reducción, en paralelo, del porcentaje de emprendedores potenciales. El Gráfico 4 ilustra estos resultados.

\section{Gráfico 4. Evolución del porcentaje de población de 18-64 años que espera emprender en los próximos tres años y la Tasa de Actividad Emprendedora (TEA) en España. Periodo 2005-2015}

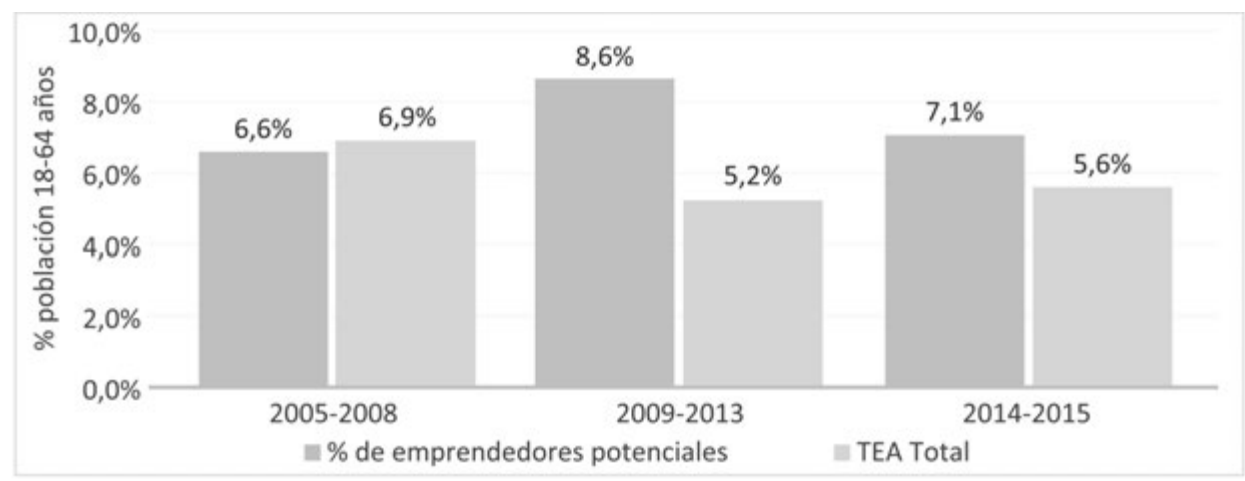

Fuente: elaboración propia a partir de los datos del GEM.

\footnotetext{
${ }^{3}$ Véase Shane y Venkataraman (2000).
} 
Otro aspecto interesante es el analisis de la evolución de los emprendedores nacientes (menos de 3 meses de actividad) y los nuevos ( de 3 a 42 meses). Como se observa en el gráfico 5 la crísis ha afectado negativamente a los emprendedores que se encuentran en ambas fases del proceso, pero con especial intensidad a los nuevos, que se encontraban en fase de consolidación. Durante la recesión los emprendedores nacientes se han reducido desde el 3,1\% de la población adulta al $2,9 \%$ (lo que supone una caída del 6\%). En lo que se refiere a los emprendedores nuevos, la crisis ha dificultado sensiblemene su consolidación, lo que ha generado un retroceso muy importante, desde 3,9\% en el periodo expansivo 2005-2008 hasta el 2,4\% en plena crisis (lo que equivale a una reducción del 39\%). El inicio de la recuperación económica ha supuesto una cierta mejora, si bien no ha permitido todavía que se vuelva a niveles previos a esta. Fruto de lo expuesto, se ha producido una reducción del ratio de empresas nacientes con respecto a las consolidadas (de 0,44 a 0,36).

\section{Gráfico 5. Evolución porcentaje de la población 18-64 años involucrada en negocios nacientes y nuevos en España. Periodo 2005-2015}

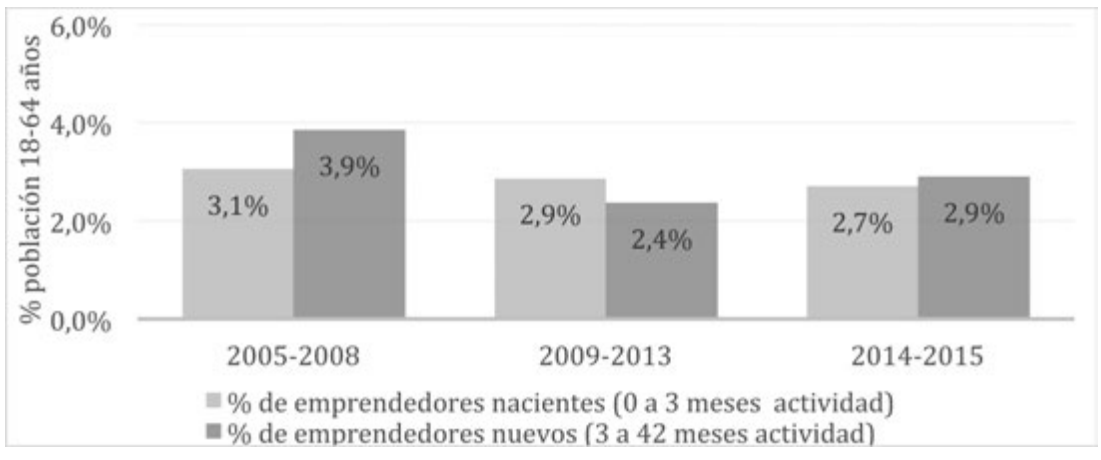

Fuente: elaboración propia a partir de los datos del GEM.

Tambien se observa un impacto muy importante de la recesión sobre la tasa de abandono de empresas (porcentaje de empresas que ha cerrado o abandonado su actividad en los últimos 12 meses) y la tasa de cierre (porcentaje de empresas que ha cerrado y cuya actividad no ha sido continuada por otros). Como se observa en el Gráfico 6 la tasa de abandono pasó del 1,2\% (2005-2008) al 2\% en plena recesión, lo que supuso un incremento del $65 \%$. Dado que 1 de cada 3 negocios eran traspasados con o sin cambio de actividad, la tasa real de cierre de empresas se situó en el 1,3\% en media anual durante la recesión, cifra muy superior al 0,8\% que tuvo lugar en el periodo precedente. El inicio de la recuperación económica ha permitido una reducción de ambas tasas, si bien todavía lejos de su nivel precrisis. 
Gráfico 6. Evolución del porcentaje de población de 18-64 años que ha abandonado o cerrado un negocio en los últimos 12 meses en España. Periodo 2005-2015

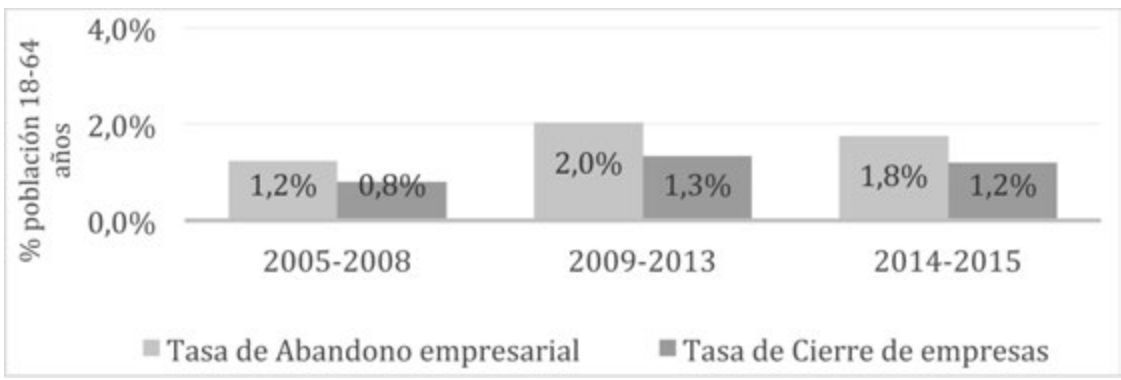

Fuente: elaboración propia a partir de los datos del GEM.

El principal motivo de abandono de la actividad empresarial durante la crisis económica fue la falta de rentabilidad del negocio, que causó casi la mitad de los abandonos, cifra muy superior a su equivalente durante 2007-08 en el que ésta afectaba a 3 de cada 10 empresas. Los problemas para obtener financiación se situaron en segundo lugar representando el 14,7\% de los abandonos -véase la Tabla 3-.

Tabla 3. Principales motivos de abandono de la actividad empresarial. Periodo 2005-2015

\begin{tabular}{|l|c|c|c|}
\hline \multicolumn{1}{|c|}{ MOTIVO } & $2007-2008$ & $2009-2013$ & $2014-2015$ \\
\hline Oportunidad de vender el negocio & $7,7 \%$ & $4,8 \%$ & $2,1 \%$ \\
\hline El negocio no era rentable & $29,8 \%$ & $48,3 \%$ & $47,6 \%$ \\
\hline Problemas para obtener financiación & $13,0 \%$ & $14,7 \%$ & $10,1 \%$ \\
\hline Otro trabajo u oportunidad de negocio & $5,0 \%$ & $3,8 \%$ & $8,7 \%$ \\
\hline El cierre fue planificado con antelación & $3,2 \%$ & $1,4 \%$ & $1,1 \%$ \\
\hline Jubilación & $6,1 \%$ & $3,2 \%$ & $8,6 \%$ \\
\hline Razones personales & $16,1 \%$ & $10,1 \%$ & $8,8 \%$ \\
\hline
\end{tabular}

Fuente: elaboración propia a partir de los datos del GEM

Un aspecto relevante a considerar es cuales son los motivos fundamentales para emprender y su evolución con el ciclo económico. El GEM considera dos razones principales: por necesidad y por oportunidad. El emprendedor por necesidad es aquel que se encuentra inmerso en el proceso emprendedor por no 
tener una mejor opción en el mercado laboral; el emprendedor por oportunidad es aquel que escoge crear una empresa, o desarrollar una actividad, basándose en la percepción de que existe una oportunidad de negocio no aprovechada -o aprovechada de forma incompleta- por las compañías existentes ${ }^{4}$.

Durante la recesión se produjo un notable incremento del emprendimiento por necesidad, derivado de la difícil situación del mercado laboral. La TEA por necesidad pasó de representar el $14,9 \%$ de las iniciativas emprendedoras en el periodo 2005-2008 al 24,4\% de media entre 2009-2013, -incrementándose un $63 \%$-. El emprendimiento basado en el aprovechamiento de las oportunidades de negocio ha continuado siendo mayoritario si bien se redujo del $80,5 \%$ al 72,7\% en el mismo periodo -véase Gráfico 7-. Pese a la salida de la recesión, en el bienio 2014-15 el emprendimiento por necesidad ha continuado en ascenso hasta representar más del $27 \%$ del conjunto de las iniciativas emprendedoras.

\section{Gráfico 7. Distribución de la actividad emprendedora (TEA) según motivo para emprender en España. Periodo 2005-2015}

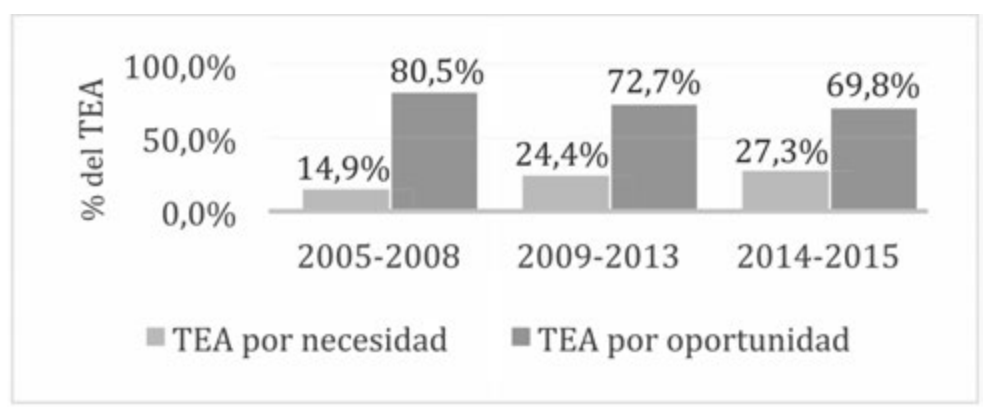

Fuente: elaboración propia a partir de los datos del GEM.

Durante el último año de recesión nuestra economía presentó importantes diferencias negativas con respecto a países homólogos -denominados economías de innovación según el estudio $\mathrm{GEM}^{5}$ - en cuanto a las tasas de emprendimiento tanto potencial como naciente y nuevo, si bien mostraba resultados favorables en relación al porcentaje de empresarios consolidados y a las tasas de abandono de empresas -véase Tabla 4-.

\footnotetext{
${ }^{4}$ Para una reflexión más extensa sobre la distinción entre ambos tipos de emprendimiento, así como su impacto económico, véase el trabajo de Acs (2006).

${ }^{5}$ El informe GEM clasifica a los países por tipo de economía según su nivel de desarrollo, respetando los criterios y parámetros definidos por el World Economic Forum. Según dichos criterios existen tres tipos de económicas: basadas en los factores de producción, en la eficiencia y en la innovación.
} 
Tabla 4. Indicadores del proceso emprendedor para economías de innovación y España en 2013

\begin{tabular}{|l|c|c|}
\hline \multicolumn{1}{|c|}{ País o área geográfica } & Economías innovación & España \\
\hline Emprendedor potencial (\%) & 14,9 & 9,4 \\
\hline Emprendedor naciente (\%) & 4,8 & 3,1 \\
\hline Emprendedor nuevo (\%) & 3,4 & 2,2 \\
\hline TEA (\%) & 8,1 & 5,2 \\
\hline Empresario consolidado (\%) & 6,9 & 8,4 \\
\hline Abandono empresarial (\%) & 1,9 & 1,4 \\
\hline
\end{tabular}

Fuente: elaboración propia a partir de los datos del GEM.

\subsection{El perfil del emprendedor}

En las siguientes líneas se analiza la evolución del perfil de las personas involucradas en el proceso emprendedor en relación a sus características demográficas entre las que se incluyen la edad, el género, el nivel de estudios y el nivel de renta.

Durante la recesión la edad media de los emprendedores potenciales e iniciales (nuevos y nacientes) se redujo algo más de un año, pasando de 37 a 35,6 años los primeros y de 39 hasta 37,8 los segundos. En ambos casos, tras la salida de la crisis se ha retornado a edades más elevadas, similares a las anteriormente existentes. La Tabla 5 muestra la evolución de la distribución de los emprendedores iniciales por grupos de edad. La recesión supuso una caída del peso de los emprendedores de mayor edad, de 55 a 64 años en beneficio de grupos más jóvenes, especialmente del colectivo de 35 a 44 años, seguido del grupo de 25 a 34 años. La salida de la crisis ha supuesto una reducción importante del colectivo de los jóvenes comprendidos entre 25 y 34 años en favor de los emprendedores de entre 35 y 54 años.

Tabla 5. Distribución por edad de los colectivos emprendedores iniciales. Periodo 2005-2015

\begin{tabular}{|l|c|c|c|}
\hline \multicolumn{1}{|c|}{ Grupos de edad } & $2005-2008$ & $2009-2013$ & $2014-2015$ \\
\hline $18-24$ años & $7,3 \%$ & $7,4 \%$ & $6,3 \%$ \\
\hline $25-34$ años & $33,8 \%$ & $34,8 \%$ & $26,3 \%$ \\
\hline $35-44$ años & $29,2 \%$ & $32,5 \%$ & $35,5 \%$ \\
\hline $45-54$ años & $18,3 \%$ & $18,8 \%$ & $23,4 \%$ \\
\hline años 55-64 & $11,2 \%$ & $6,5 \%$ & $8,6 \%$ \\
\hline
\end{tabular}

Fuente: elaboración propia a partir de los datos del GEM. 
Durante el periodo expansivo previo a la crisis, el colectivo con edades comprendidas entre 25 y 34 años era el que mantenía una mayor tasa de actividad emprendedora (10,2\%) seguido de los individuos con edades entre 35 y 44 años (8\%). La entrada en recesión a finales del 2008 supuso una pérdida de actividad emprendedora en todos los grupos de edad, pero especialmente en los colectivos de mayor edad y más jóvenes. La TEA de los individuos de 55 a 64 años se redujo a la mitad (del 4,1 al 2\%) y la de los grupos de 18 a 34 años cayó un 30\%. Tras la salida de la crisis la mayor tasa de actividad se corresponde a los individuos de 35 a 44 años $(7,4 \%)$ seguida del grupo de 25 a 34 años $(6,7 \%)$ que ve muy recortada su distancia respecto al colectivo de 45 a 54 años (5,6\%). La Tabla 6 presenta con mayor detalle las cifras anteriores. Tabla 6. Evolución del índice TEA según grupo de edad en España.
Periodo 2005-2015

\begin{tabular}{|l|c|c|c|}
\hline \multicolumn{1}{|c|}{ Grupos de Edad } & $2005-2008$ & $2009-2013$ & $2014-2015$ \\
\hline 18 a 24 años & $4,8 \%$ & $3,4 \%$ & $3,6 \%$ \\
\hline 25 a 34 años & $10,2 \%$ & $7,1 \%$ & $6,7 \%$ \\
\hline 35 a 44 años & $8,0 \%$ & $6,6 \%$ & $7,4 \%$ \\
\hline 45 a 54 años & $5,9 \%$ & $4,6 \%$ & $5,6 \%$ \\
\hline 55 a 64 años & $4,1 \%$ & $2,0 \%$ & $2,7 \%$ \\
\hline
\end{tabular}

Fuente: elaboración propia a partir de los datos del GEM.

El análisis por género de la actividad emprendedora refleja una tasa de actividad masculina superior a la femenina a lo largo de toda la década analizada. La crisis económica afectó a ambos sexos de forma intensa. No obstante, la TEA de los hombres cayó más que la de las mujeres por lo que la diferencia existente entre ambas se redujo sustancialmente. Como se observa en el Gráfico 8, antes de la crisis la diferencia era 3,4 puntos porcentuales, durante la crisis se redujo a 2,5 y con la recuperación, esta se ha situado en 1,6. Especialmente reseñable es la recuperación de la TEA femenina en el periodo 2014-15 mientras que la masculina ha continuado reduciéndose. En lo que se refiere a la distribución porcentual de emprendedores por género, el Gráfico 9 pone de manifiesto que durante la crisis aumentó ligeramente la representación masculina en detrimento de la femenina si bien tras la salida de la misma el peso de la mujer se ha incrementado sensiblemente reduciendo la brecha existente entre el porcentaje de hombres y el de mujeres a mínimos de toda la década. 
Grafico 8. Evolución del índice TEA por género en España. Periodo 2005-2015

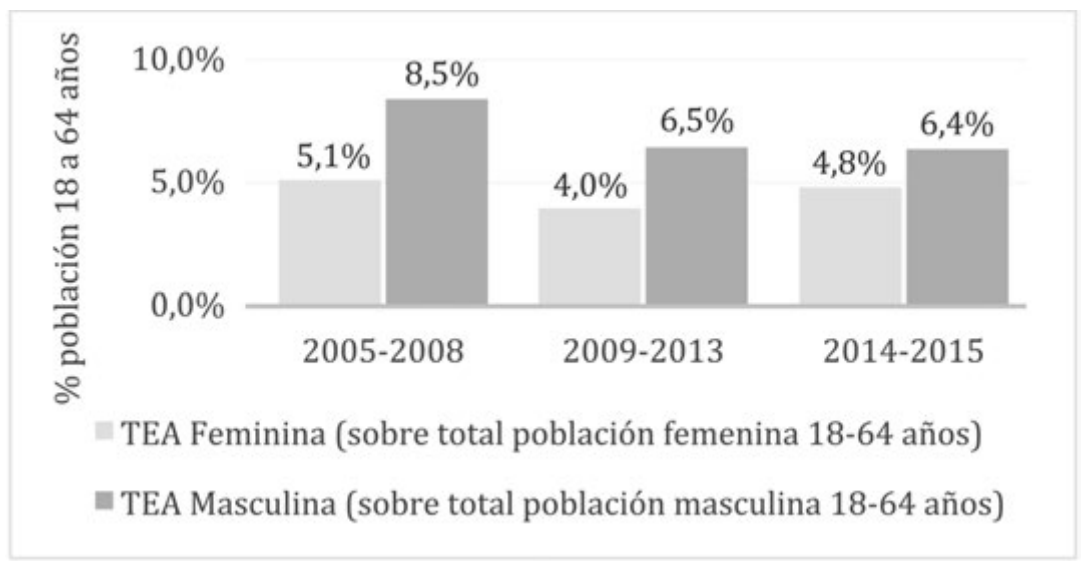

Fuente: elaboración propia a partir de los datos del GEM.

\section{Gráfico 9. Distribución de emprendedores iniciales por género en España. Periodo 2005-2015}

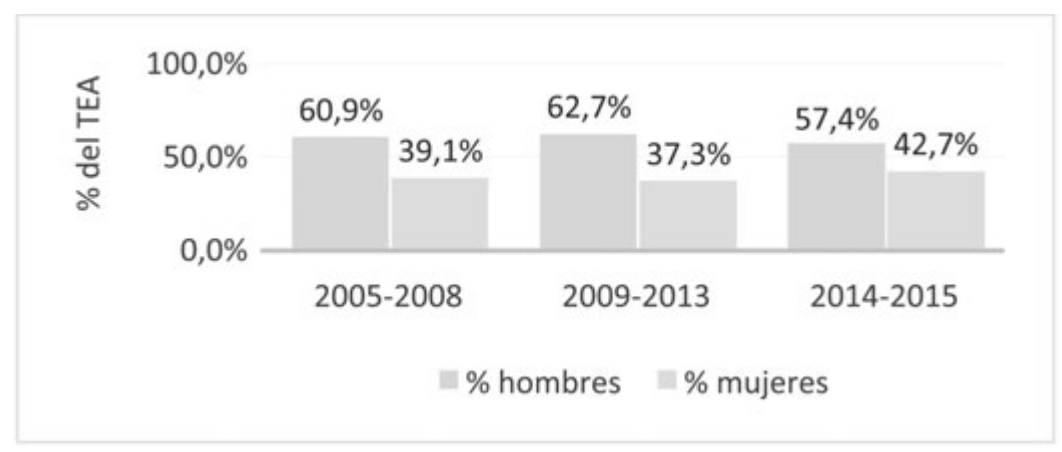

Fuente: elaboración propia a partir de los datos del GEM.

De acuerdo con los estudios del GEM se observa una relación directa entre la propensión a emprender y el nivel de formación. Así los emprendedores con educación superior han tenido una TEA más elevada que aquellos con un nivel de educación medio e inferior. La crisis económica supuso una caída similar de la actividad emprendedora para las personas de todos los niveles educativos -véase Gráfico 10-, manteniéndose las diferencias existentes entre los mismos. El cambio de ciclo ha supuesto una notable recuperación de la TEA para las personas 
de mayor nivel educativo (enseñanza superior y postgrado), que han retornado a una tasa de actividad similar a la existente en el periodo expansivo, mientras que la TEA de las personas con menor nivel educativo ha continuado disminuyendo.

\section{Gráfico 10. Evolución del índice TEA por nivel educativo en España.} Periodo 2005-2015

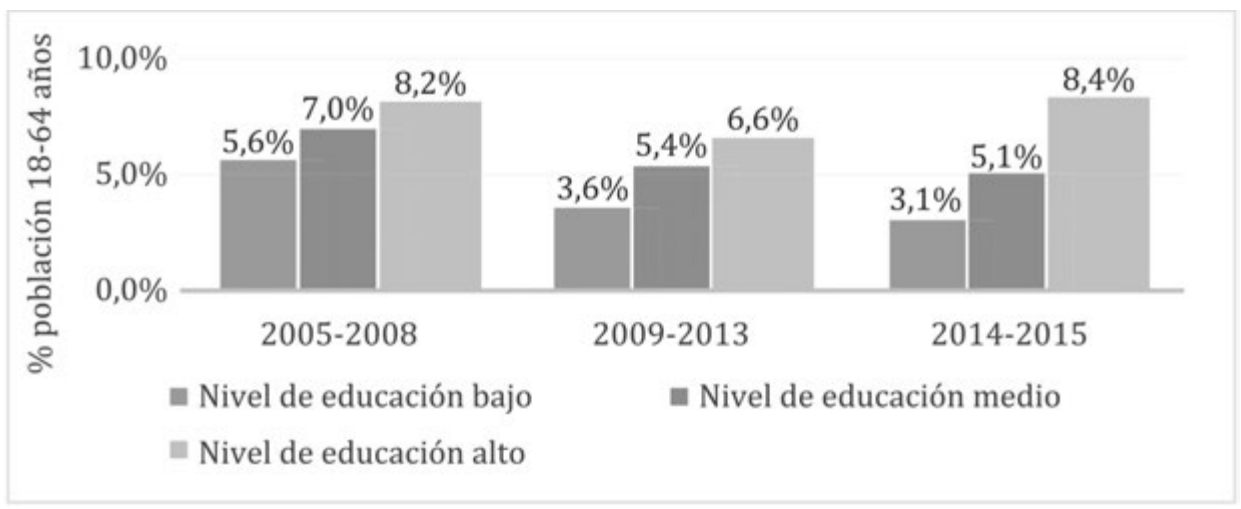

Fuente: elaboración propia a partir de los datos del GEM.

El arranque de un negocio requiere disponer de fuentes de financiación internas o externas. Es bastante común disponer al principio de fuentes internas lo que justifica que la TEA para los individuos con un mayor nivel de renta sea generalmente superior. El Gráfico 11 confirma que esto es lo acontecido en España durante el periodo 2005-2015. La crisis económica ha afectado a todos los individuos independientemente de su nivel de renta, pero ha golpeado con mayor intensidad al colectivo de renta media que ha visto caer su tasa de actividad emprendedora desde el 8,1\% hasta el 4,8\%. Con la recuperación económica, los individuos con un nivel de renta superior han conseguido incrementar su tasa de actividad al 9,2\%, por encima de sus valores previos a la recesión por lo que la brecha entre el nivel de emprendimiento de los individuos con mayor nivel de renta y el resto se ha ampliado notablemente. 


\section{Gráfico 11. Evolución del índice TEA por nivel de renta en España.} Periodo 2005-2015

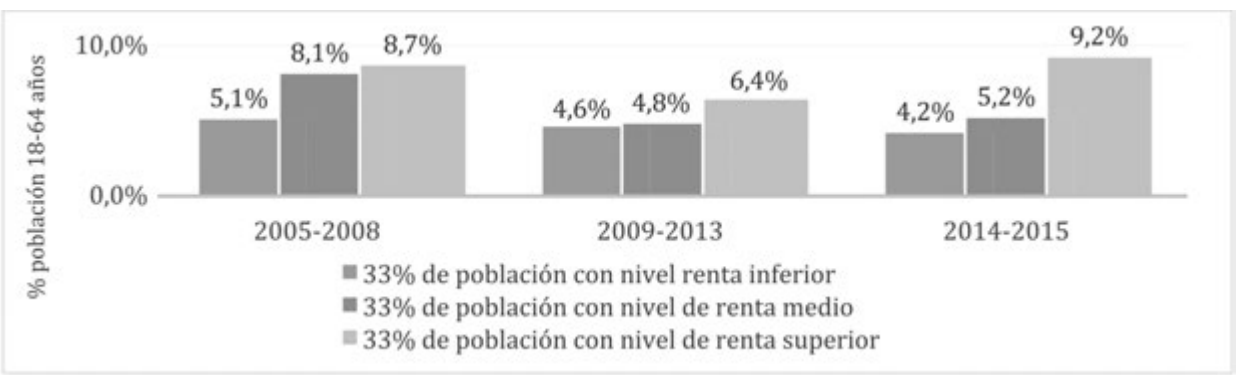

Fuente: elaboración propia a partir de los datos del GEM.

En lo que respecta a la financiación de los proyectos de negocio puestos en marcha por los emprendedores nacientes en España, se pone de manifiesto que la crisis económica vino acompañada de reducción del capital semilla necesario para desarrollar una iniciativa emprendedora, así como un menor importe asumido por el emprendedor. Tras la salida de la crisis se ha mantenido la misma tendencia decreciente -véase Gráfico 12-.

\section{Gráfico 12. Evolución del capital semilla de los proyectos emprendedores. Periodo 2005-2015}

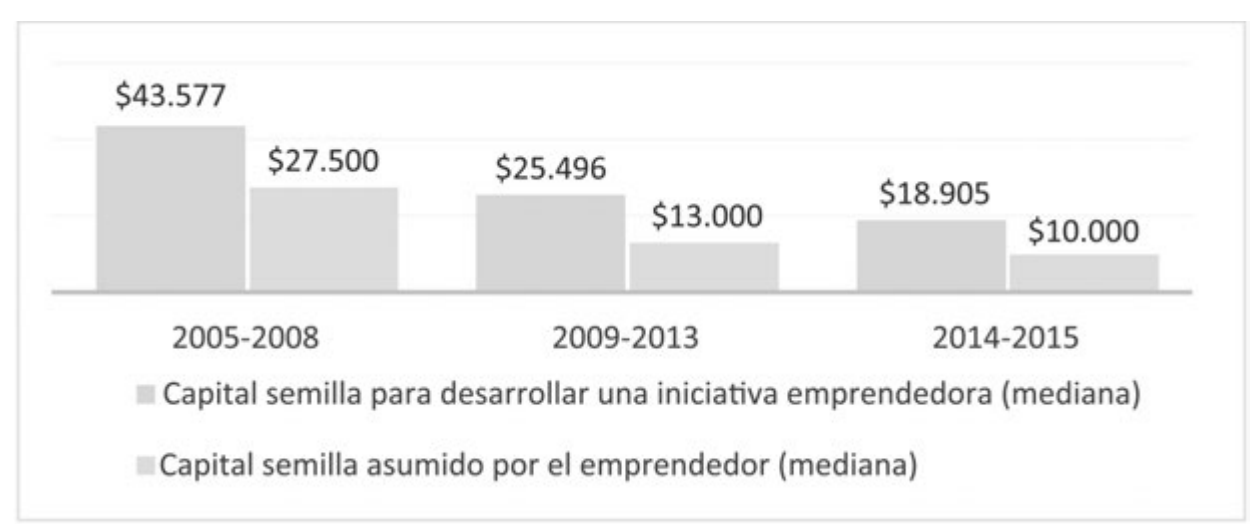

Fuente: Elaboración propia a partir de los datos del GEM.

En relación a los inversores, se observa un importante crecimiento en términos porcentuales de la población que ha participado en los tres años anteriores como inversor privado en algún proyecto de negocio liderado por otra persona. 
En general invierten a título personal, pero no participan en la gestión de forma directa. La inversión puede ser profesionalizada o no, en este último caso movidos por la confianza en la persona que emprende. La inversión privada ha tenido en general un protagonismo superior durante la recesión. En el periodo de crisis (2008-2013) se pasado del 2,8\% al 3,4\% de la población adulta que actuó como inversor privado.

\subsection{Las aspiraciones de la actividad emprendedora}

La caída de la actividad económica supuso un impacto sobre las características de los nuevos negocios creados en España en cuanto a su actividad económica, sus expectativas de crecimiento y su orientación innovadora e internacional. Los negocios que han iniciado su actividad emprendedora en la última década lo han hecho, mayoritariamente, con un tamaño modesto y con escasas ambiciones para crecer, evitando el riesgo de innovar y de entrar en nuevos mercados para crecer, enfocándose hacia actividades tradicionales y concentrándose en los mercados locales, lo que provoca una reducción del número de empresas denominadas high growth. Algunos autores consideran que las aspiraciones de las personas para crecer en su negocio dependen del contexto. Según esta literatura, el funcionamiento de los mercados y las instituciones juegan un papel fundamental para potenciar las aspiraciones de las personas en cuanto al crecimiento empresarial ${ }^{6}$. Si nos enfrentamos a sistemas con escasa protección de derechos de la propiedad intelectual o la existencia notable de comportamientos de corrupción, ello tendrá una influencia negativa en las aspiraciones de crecimiento de los proyectos de emprendimiento. La aspiración para hacer crecer un negocio tiene una cierta relación con la motivación para lanzar una empresa. La motivación para aumentar el nivel de ingresos de las personas emprendedoras va asociada con un mayor crecimiento real de la empresa y una mayor orientación exportadora ${ }^{7}$. En definitiva, existe una relación no sencilla de entender entre el contexto para emprender, la motivación de los individuos para lanzarse a la aventura de crear un negocio, el crecimiento real experimentado por la nueva empresa y su comportamiento (mercado local versus internacional).

Por todo ello es fundamental abordar una serie de cuestiones relacionadas con las aspiraciones de la actividad emprendedora en España entre las que se encuentran: (1) en qué sectores de actividad económica se concentra el emprendimiento, (2) con que tamaño de empleo se inicia la aventura empresarial, (3) qué proporción de los negocios aspiran realmente a crecer, (4) la vocación inno-

${ }^{6}$ Véase Estrin et al. (2013).

${ }^{7}$ Véase Hessels et al. (2008). 
vadora de los proyectos emprendedores y (5) el deseo de competir en mercados internacionales de los proyectos innovadores.

En cuanto a los aspectos generales del negocio, la recesión ha generado una reducción de la tasa de actividad empresarial de forma generalizada en los distintos sectores económicos. El sector transformador ha sufrido una caída en su TEA del 50\% (del $2 \%$ al $1 \%$ ), y en el extractivo la reducción ha sido todavía mayor en términos porcentuales. También se ha reducido notablemente el porcentaje de emprendedores en el sector de servicios a empresas, pasando su TEA del 1,8\% al 1,2\%,-lo que significa una cada de un 33\%-. El sector que mejor ha aguantado la crisis ha sido el de actividades orientadas al consumo, cuya TEA se ha reducido tan solo del 3\% al 2,8\%. El periodo de expansión ha venido acompañado de un incremento de la actividad importante en el sector de servicios a empresas seguido por el de consumo, sin que en ninguno de los dos casos se llegue a alcanzar el nivel pre crisis. Si se considera la distribución porcentual de la actividad emprendedora por sectores, se puede observar en el Gráfico 13, que en la década comprendida entre 2006 y 2015 se ha incrementado notablemente el porcentaje de nuevas iniciativas que se concentran en los sectores de servicios a empresas y comercio (bienes de consumo) dirigido a consumidores finales.

Durante los 5 años de duración de la crisis ha crecido en gran medida el peso del sector orientado al consumo, que ha pasado de representar el $41 \%$ a casi el $53 \%$ de las nuevas iniciativas emprendedoras. En paralelo la transformadora y extractiva perdían peso. Tras la salida de la crisis el sector de servicios a empresas ha aumentado su representatividad por encima del 29\% de las iniciativas emprendedoras, en detrimento del transformador que ha pasado de representar el $27,7 \%$ a tan solo el $14,8 \%$.

\section{Gráfico 13. Distribución de emprendedores iniciales según sector de actividad. Periodo 2006-2015}

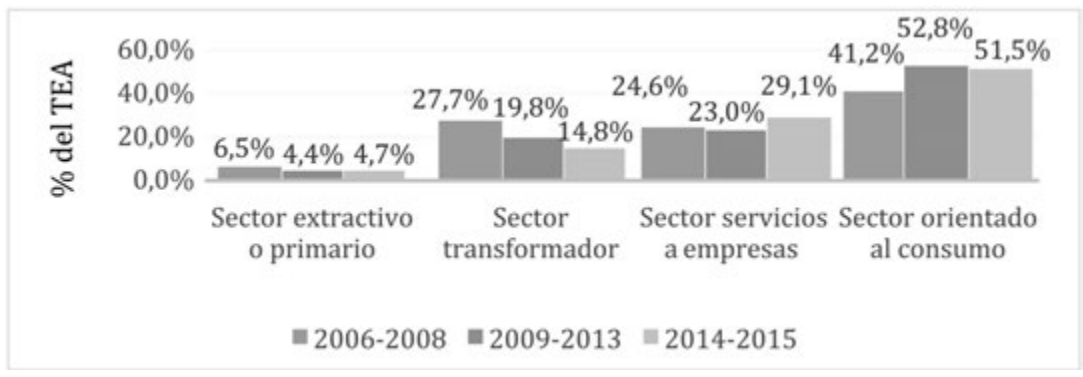

Fuente: elaboración propia a partir de los datos del GEM.

La crisis económica ha tenido como consecuencia fundamental que las nuevas empresas nazcan con un tamaño promedio inferior al que lo hacían cuando la 
economía atravesaba el ciclo expansivo y que además se encuentren con dificultades para crecer. La mayoría de las empresas nacen y se mantienen pequeñas ${ }^{8}$. Durante la recesión las iniciativas emprendedoras sin empleados han incrementado su TEA un $20 \%$ (de 2,5\% a 3\%), mientras que las nuevas empresas de 1 a 5 empleados lo han visto reducido casi un 50\% (de $3,7 \%$ a $1,9 \%$ ). Esto podría estar relacionado con el hecho de que un número creciente de las nuevas empresas se orientaban a la generación de autoempleo. Como consecuencia de lo expuesto, entre 2009 y 2013 el porcentaje de nuevos negocios sin empleados creció notablemente pasando a representar el 57,3\% (frente al 34,7\% del periodo 2006-2008 anterior). El Gráfico 14 muestra la distribución porcentual de las empresas según su tamaño antes, durante y después de la recesión. El porcentaje de empresas con menos de 6 empleados creció durante la crisis desde el 85,5\% hasta el 93,1\%. Durante el año 2011 el número de empresas nuevas sin empleados superó el 70\% (máximo de la década). Las empresas nuevas con más de 6 empleados se redujeron desde el 16,9\% en 2008 a menos de la mitad (8,3\% en 2013), esta cifra ha continuado reduciéndose hasta el 4,6\% en 2015.

\section{Gráfico 14. Distribución de emprendedores iniciales por número de empleos. Periodo 2006-2015}

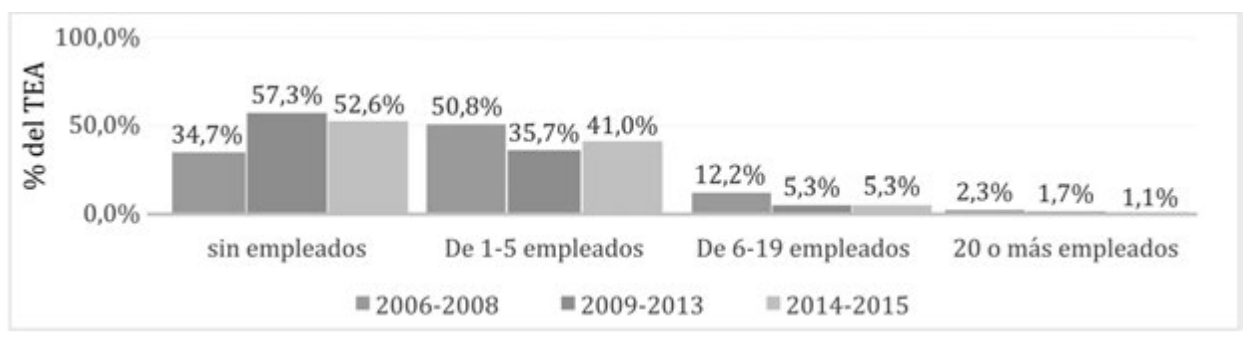

Fuente: elaboración propia a partir de los datos del GEM.

En lo que se refiere a las expectativas de crecimiento, basado en el número de empleados que la empresa espera tener en los próximos cinco años, se observa la existencia de tasas modestas de personas emprendedoras que aspiran a hacer crecer su empresa de forma rápida. En 2008 había un 6,2\% de empresas que no sabían el número de empleados de los que dispondrían, en 2013 esta cifra superó el 16\% (el máximo se alcanzó en 2011 con el 22,6\%). El porcentaje de emprendedores en fase inicial que preveía tener más de 5 trabajadores se ha reducido, desde el 22,2\% antes de la crisis hasta el 15,2\% durante la misma (alcanzando su mínimo en 2012 con el $12,7 \%$ ). Es decir, la recesión genera no solo un alto grado de incertidumbre en

\footnotetext{
${ }^{8}$ Conviene recalcar que en general, el tamaño de las empresas en España es pequeño. Según los datos del Directorio Central de Empresas (DIRCE) publicado el 1 de enero de 2016, el 55\% de los más de 3.236.000 empresas españolas existentes no tenían ningún asalariado y tan solo 7,9\% tenía más de 5 .
} 
cuanto al crecimiento de las nuevas empresas, sino que además este es débil debido a las bajas expectativas de las compañías para generar nuevos puestos de trabajo.

En relación a la orientación innovadora, hay que considerar que muchos emprendedores no inician sus negocios por una idea innovadora, sino como resultado de una idea imitadora de otra actividad. No obstante, los proyectos novedosos, aunque minoritarios, en ocasiones generan la catarsis y a veces la revolución de un mercado o sector. Y viceversa, el entorno puede inhibir o favorecer la actividad emprendedora en clave de innovación ${ }^{9}$.

Según los datos de publicados en el GEM España 2015, tan solo un 10,6\% de las empresas en su fase inicial ofrecen productos o servicios completamente innovadores, lo cual representa la cifra más baja de la última década. La crisis económica ha venido acompañada de actividades emprendedoras que han incorporado menos productos y servicios innovadores. El Gráfico 15 muestra que durante el periodo comprendido 2009-2013 las iniciativas completamente innovadoras se redujeron del 18,4\% al 16,1\% y además han continuado disminuyendo tras el inicio de la recuperación. También las iniciativas algo innovadoras han visto reducida su representación desde el 29,2\% hasta el 19,6\% durante la recesión.

Las cifras anteriores significan que el porcentaje de población de 18 a 64 años que puso en marcha iniciativas completamente emprendedoras en España se redujo desde el 1,4\% hasta el 0,9\%.

\section{Gráfico 15. Distribución de los emprendedores iniciales por el grado de novedad de sus productos y servicios en España. Periodo 2005-2015}

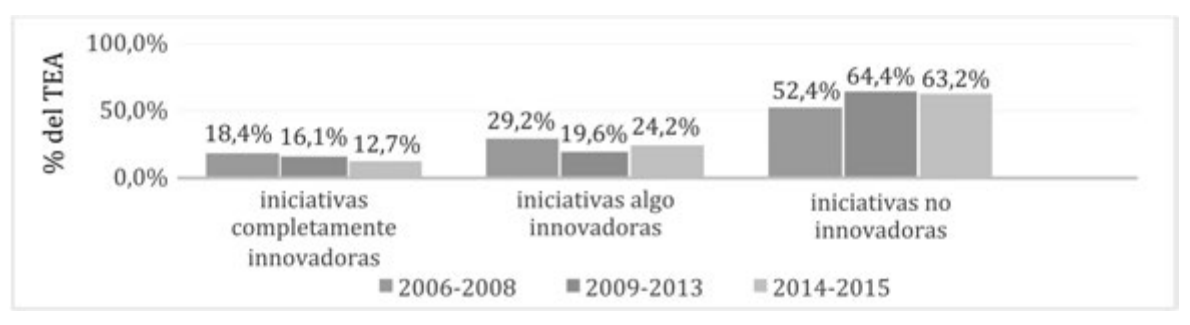

Fuente: elaboración propia a partir de los datos del GEM.

Con respecto al desarrollo y aplicación de nuevas tecnologías por parte de los emprendedores en fase inicial, entre 2005 y 2008 el 20,6\% de los mismos se apoyaban en tecnologías con un nivel de obsolescencia inferior a los 5 años -véase Gráfico 16-. La crisis económica elevó este porcentaje hasta el 30,3\%. En general, los colectivos de emprendedores con negocios consolidados tienen unas tasas

\footnotetext{
${ }^{9}$ Véase González Pernía et al. (2015).
} 
muy superiores de utilización de tecnologías más obsoletas (86,6\% de más de 5 años frente al 70,3\% en 2015).

\section{Gráfico 16. Distribución de los emprendedores iniciales por la antigüedad de las tecnologías utilizadas. Periodo 2005-2015}

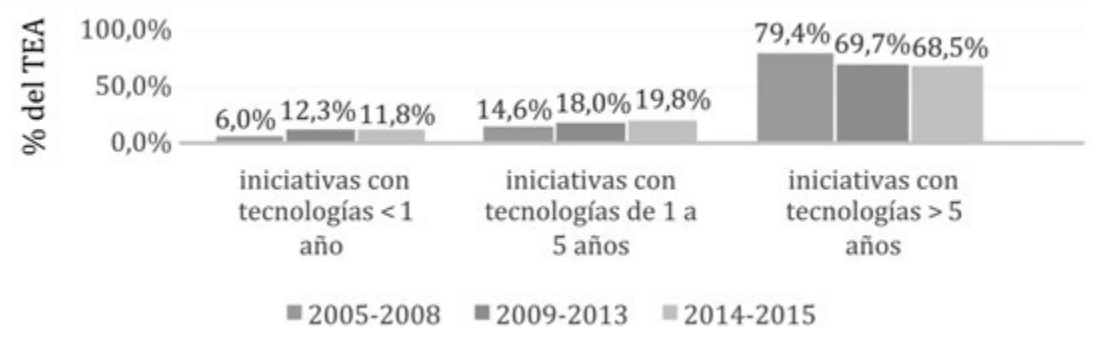

Fuente: elaboración propia a partir de los datos del GEM.

La crisis ha favorecido la búsqueda de mercados con un menor nivel de competencia para incrementar las posibilidades de éxito. Como se muestra en el Gráfico 17, el porcentaje de emprendedores que dicen enfrentarse a un nivel de competencia reducida o nula durante la recesión aumentó del 39,2\% al 47,7\%.

\section{Gráfico 17. Distribución de los emprendedores iniciales según la competencia percibida en el mercado en España. Periodo 2005-2015}

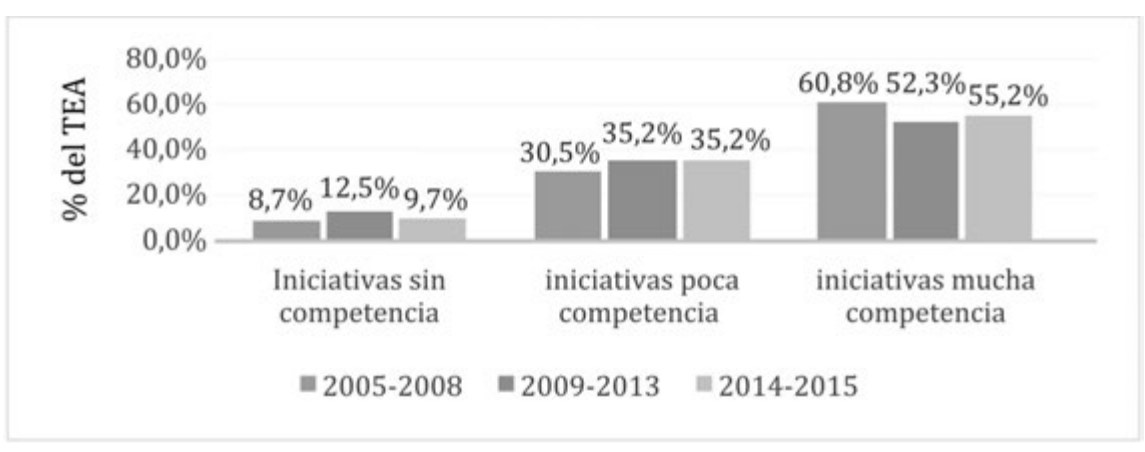

Fuente: elaboración propia a partir de los datos del GEM.

La apertura de las empresas hacia el exterior es una tendencia clave en nuestra sociedad. Por ello, el grado de internacionalización de los nuevos proyectos emprendedores resulta fundamental. Los datos del GEM ponen de manifiesto que la actividad emprendedora en su fase inicial tiene un carácter cada vez más 
marcadamente local. Las iniciativas emprendedoras que exportaban algo se vieron reducidas desde el 40,1\% en el periodo pre crisis hasta el 26,2\% -véase Gráfico 18-. Ello significa que 3 de cada 4 empresas no exportaban nada de su producción. Si se pone el foco en las iniciativas con un carácter más internacional, aquellas que exportan al menos el $25 \%$ de su producción, estas se han reducido en torno al 50\% pasando de representar a 2 de cada 10 emprendedores a tan solo 1 de cada 10. Si se analiza la TEA en función del grado de internacionalización de las empresas se observa una caída superior al 50\% (desde el 3,1\% al 1,4\%) de la población adulta que emprendió con una orientación algo internacional durante la crisis. Los emprendedores con clara vocación internacional (que exportan más de un $25 \%$ de la producción) pasaron de representar el 1,5\% de la población entre 18 y 64 años a tan solo el 0,5\%. lo cual equivale a una reducción del 65\%.

El GEM España del año 2013 publicó los resultados de un benchmarking internacional en el que se comparaba la situación de nuestro país con la media de los países innovadores en cuanto a expectativas de crecimiento y orientación innovadora e internaciona ${ }^{10}$. De su análisis se desprende que el porcentaje de emprendedores españoles en fase inicial, que ofrece servicios a empresas y orientados al consumidor (aproximadamente el $81 \%$ ) era superior a la media de las economías basadas en la innovación (75,5\%).

También se observa que la tasa de emprendedores españoles en fase inicial que ofrece productos o servicios completamente nuevos para sus clientes es casi 3 puntos inferior a la media de las economías similares a la nuestra, un $14,7 \%$ frente al 17,4\%. Por último, en cuanto a las aspiraciones a crecer (más de 5 empleos en los próximos 5 años) el porcentaje de emprendedores españoles alcanzó el 15\% frente al 26\% de nuestros homólogos.

\section{Gráfico 18. Distribución de emprendedores iniciales según orientación internacional en España. Periodo 2005-2015}

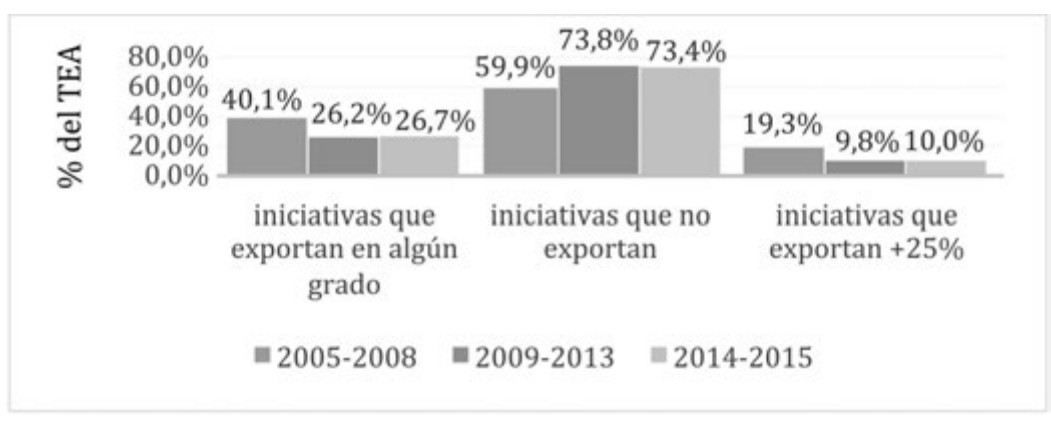

Fuente: elaboración propia a partir de los datos del GEM.

${ }^{10}$ Véase GEM (2013). 
En síntesis, la actividad emprendedora española en comparación con otros países de características similares en el momento de finalización de la crisis se caracterizaba por su definida orientación hacia sectores de servicios dirigidos a empresas y consumo, por su menor grado de novedad en los productos y servicios desarrollados, por su modesta vocación internacional y por la débil ambición de lograr un negocio de al menos 5 empleados.

\subsection{El entorno emprendedor}

La literatura sobre emprendimiento otorga un papel muy importe al entorno tanto en lo que se refiere al fomento de la actividad emprendedora como en su impacto en el desarrollo económico de un territorio ${ }^{11}$. Algunos autores consideran que no solo es preciso que el marco institucional promueva la cultura emprendedora de un territorio ${ }^{12}$, sino también de la cooperación entre los emprendedores, las organizaciones y los agentes del entorno, lo que va configurando el "ecosistema emprendedor". En general este término se emplea para conocer las condiciones más adecuadas para emprender en ciertos entornos ${ }^{13}$.

Ello implica analizar las interconexiones entre las empresas emprendedoras potenciales nacientes y existentes), con los agentes financiadores (empresas, venture capitalists, business angels, bancos) y de organizaciones promotoras (como universidades o agencias del sector público) asociadas a la diversidad de iniciativas emprendedoras orientadas a generar valor ${ }^{14}$.

El estudio GEM realiza el diagnóstico de una serie de condiciones del entorno para emprender en cada país a través de la opinión de un grupo de expertos que son encuestados anualmente. Estos expresan su opinión respecto a las condiciones indicadas anteriormente por medio de un cuestionario (escala Likert de 5 puntos: 1 = completamente falso; 5 = completamente cierto). El gráfico 19 muestra las condiciones del entorno analizadas, así como los valores medios otorgados por los expertos para cada una de ellas en los periodos 2005-2008 (fase expansiva) y 2009-2013 (fase recesiva). La mayoría de las condiciones del entorno español estudiadas por los expertos reciben una valoración inferior a 3 puntos sobre 5 durante la crisis económica, a excepción del acceso a la infraestructura física y de servicios. En dicho periodo, la educación y la formación emprendedora en la etapa escolar es la condición peor valorada ( 1,5 puntos), seguida por la financiación para emprendedores $(2,0)$. Tampoco aprueban según los expertos la transferencia de $\mathrm{I}+\mathrm{D}$, las políticas gubernamentales en cuanto a burocracias e impuestos, la

\footnotetext{
${ }^{11}$ Véase Mason y Brown (2014).

${ }^{12}$ Véase Veciana y Urbano (2008) o Welter y Smallbone (2011).

${ }^{13}$ Véase Herrmann et al. (20129 o Mason y Brown (2014).

${ }^{14}$ Véase ACS et al. (2015).
} 
educación en la etapa post escolar, las barreras de acceso al mercado interno ni las políticas gubernamentales relacionadas con el emprendimiento como prioridad y su apoyo. El análisis dinámico pone de manifiesto que según el citado panel de expertos la recesión económica supuso un empeoramiento de todas las condiciones del entorno a excepción de la infraestructura física y de servicios y la dinámica del mercado interno. Una revisión más detallada de estas valoraciones revela que los aspectos del entorno peor valorados durante la crisis económica, también lo son en términos medios durante toda la década, lo cual significa que, aunque la recesión haya empeorado las condiciones del entorno, dichos problemas no son generados por la misma, sino que tienen un carácter estructural y como tal deben ser abordados.

\section{Gráfico 19. Valoración media de los expertos entrevistados sobre las condiciones del entorno para emprender en España. Comparación periodos 2005-2008 y 2009-2013}

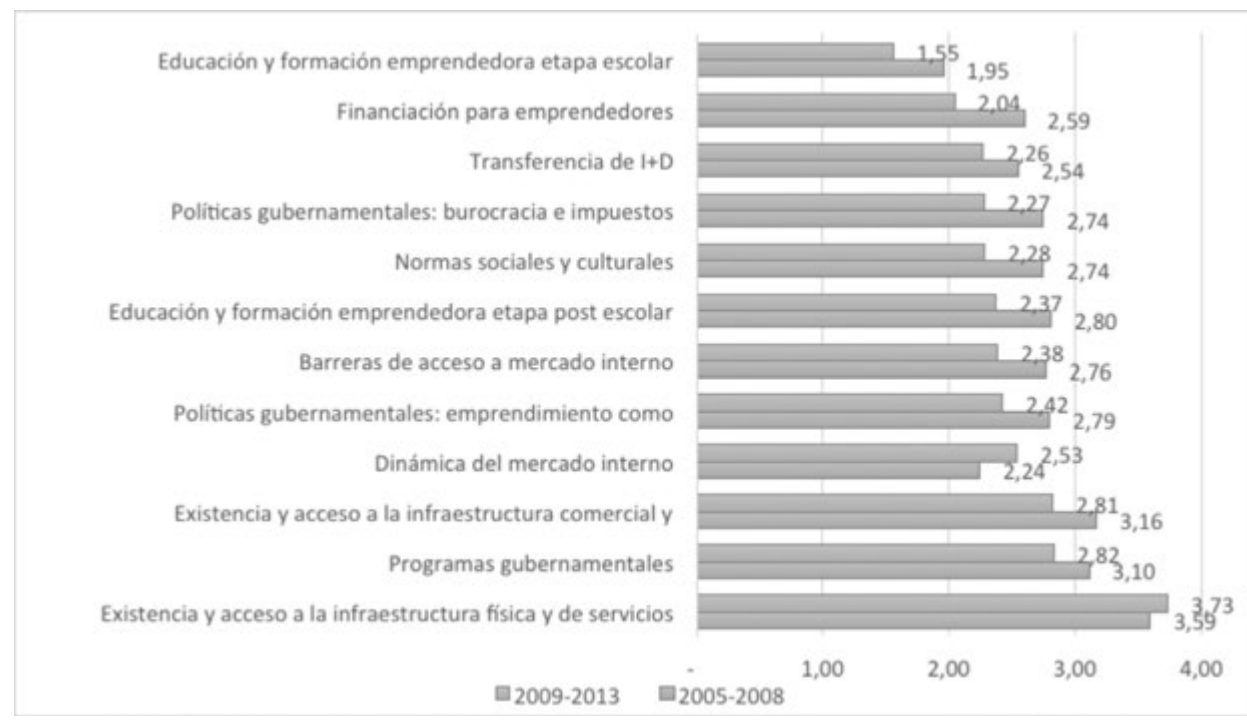

Fuente: elaboración propia a partir de los datos del GEM.

Los principales obstáculos que se encontró la actividad emprendedora en España durante la crisis económica, según los expertos entrevistados en el GEM, fueron el apoyo financiero ( $71,5 \%$ de los encuestados), las políticas gubernamentales $(50,8 \%)$ y el clima económico/crisis económica $(38,5 \%)$. Si se analiza la evolución de los obstáculos al emprendimiento en un periodo más amplio (20052015), se concluye que los factores anteriores unido a la educación y formación de los emprendedores han ocupado las primeras posiciones en el ranking de los 
frenos al emprendimiento, por lo que convendría profundizar en la toma de medidas estructurales que favorezcan una solución a los mismos.

Entre las condiciones del entorno que han favorecido la actividad emprendedora en España durante la recesión se encuentran, según los expertos, la crisis económica, las políticas y los programas gubernamentales, la educación/formación de los emprendedores, el estado del mercado laboral y el apoyo financiero. A partir de estas opiniones conviene establecer algunos matices. En primer lugar, los entrevistados reconocen que los emprendedores cada vez tienen más formación, así como que se esfuerzan en participar en algún programa formativo relacionado con el emprendimiento. En segundo término, durante los últimos años (especialmente en el periodo 2009-13), los expertos coinciden en que la recesión económica ha sido una de las condiciones que ha favorecido la actividad emprendedora. Sin embargo, el efecto de este tipo de condiciones en la actividad emprendedora suele ser muy complejo y ambiguo ${ }^{15}$. Incluso en ocasiones se ha evidenciado que regiones con altos niveles de desempleo en etapas de recesión pueden experimentar un incremento en el emprendimiento. Por último, conviene subrayar que a pesar de la necesidad de financiación que se evidenció entre los obstáculos, los expertos entrevistados también reconocen la existencia de fórmulas de financiación que han servido de apoyo a la actividad emprendedora tales como el papel activo de los inversores de capital privado y la existencia de algunos programas de acompañamiento con financiación que se aplica a un número reducido de proyectos emprendedores ${ }^{16}$.

\section{CONCLUSIONES}

La recesión que ha sufrido la economía española entre 2008 y 2013 ha tenido consecuencias relevantes sobre el emprendimiento en nuestro país, afectando a los valores, percepciones y aptitudes emprendedoras de la población, a su actividad emprendedora y las aspiraciones asociadas a la misma, al perfil sociodemográfico de los nuevos emprendedores y al contexto en el que se desarrolla el proceso emprendedor.

En lo referente a los valores, percepciones y aptitudes emprendedoras de la población, la negativa coyuntura económica ha supuesto una caída de las oportunidades emprendedoras percibidas por la población, así como una menor percepción de modelos de referencia de otros emprendedores, lo cual ha generado un cierto desincentivo al emprendimiento, al reducirse el efecto imitación y de

\footnotetext{
${ }^{15}$ Véase Audretsch y Thurik (2001), Evans y Leighton (1990) o Audretsch y Fritsch (1994).

${ }^{16}$ De los Ríos et al. (2015) desarrollan la importancia del sector público en el estímulo de la actividad emprendedora.
} 
creación de redes de emprendedores. En paralelo se ha observado una disminución intensa del miedo al fracaso a la hora de emprender por parte de la población involucrada en este proceso, probablemente acompañada de una mayor capacidad de asunción de riesgos, así como un esfuerzo para formarse y tener mayores probabilidades de éxito ante una coyuntura tan negativa.

La opinión de los españoles acerca de que ser emprendedor sea una buena opción profesional ha mantenido una continua tendencia a la baja a lo largo de toda la década. Ser emprendedor está cada vez menos valorado en la sociedad española. De forma puntual, durante la crisis se produjo un aumento de la población que percibió que emprender brindaba un mayor estatus económico, en contra de la tendencia existente, si bien esta percepción no ha tenido continuidad con el cambio de ciclo.

Del análisis del impacto de la crisis económica sobre la actividad emprendedora se desprende en primer término que durante la recesión el porcentaje de emprendedores potenciales en España se incrementó, probablemente por razones de necesidad, planteado en términos de autoempleo como una alternativa a las dificultades del mercado laboral. La crisis ha afectado negativamente al porcentaje de emprendedores que se encuentran en las distintas fases del proceso emprendedor (TEA) pero con especial intensidad a los nuevos, que se encontraban en fase de consolidación. También se observa un impacto muy importante sobre la tasa de abandono y de cierre de empresas, motivado en gran medida por la falta de rentabilidad del negocio.

El perfil sociodemográfico de los emprendedores españoles se ha visto alterado por la recesión debido a que esta ha afectado a los individuos de manera diversa en función de su edad, sexo, formación y renta. La edad media de los emprendedores potenciales e iniciales se redujo en algo más de un año, debido a una caída en el peso relativo de los emprendedores de mayor edad (55 a 64 años) en beneficio del colectivo más joven, especialmente de 35 a 44 años. Ambos sexos se vieron afectados de forma intensa. No obstante, la TEA masculina cayó más que la femenina por lo que la diferencia existente entre ambos géneros se redujo sustancialmente. Con el inicio de la recuperación económica el porcentaje de mujeres emprendedoras se ha incrementado sensiblemente reduciendo la brecha existente a mínimos de toda la década. Las dificultades económicas afectaron a la TEA con independencia del nivel educativo de las personas, no obstante, la salida de la crisis ha ido acompañada de una notable recuperación de actividad emprendedora de las personas con mayor formación, mientras que en el caso de las personas con menor nivel educativo esta ha continuado disminuyendo. Se puede afirmar que se ha mantenido una relación directa entre la propensión a emprender y el nivel educativo. La coyuntura negativa ha golpeado con mayor intensidad al colectivo de renta media. En el bienio 2014-15 los individuos con un nivel de renta superior han conseguido incrementar su tasa de actividad por 
encima de sus valores previos a la recesión por lo que ha aumentado la brecha entre el nivel de emprendimiento de los individuos con mayor nivel de renta y el resto.

La crisis económica vino acompañada de una reducción del capital semilla necesario para desarrollar iniciativas emprendedoras, así como un menor importe asumido por el emprendedor. Además, la inversión privada ha tenido en general un protagonismo superior, al menos en términos de población implicada en realizar inversiones para proyectos de terceros.

En relación a las aspiraciones asociadas a la actividad emprendedora cabe destacar que durante la crisis el tejido emprendedor ha avanzado hacia la tercerización de la economía, la presencia de proyectos emprendedores de menor tamaño, con escasa motivación para crecer, con menor proyección internacionalmente y con una innovación y desarrollo tecnológico aún insuficiente.

En referencia al entorno emprendedor los expertos entrevistados en el GEM opinan que las condiciones del mismo no favorecen de forma adecuada el impulso de nuevas iniciativas, que se trata de un problema estructural y que la recesión económica supuso un empeoramiento de casi todas las condiciones del entorno. La falta de apoyo financiero, las políticas gubernamentales y el clima económico/ crisis económica, fueron los principales obstáculos que se encontró la actividad emprendedora en España durante el periodo 2009-2013.

En este panorama se requiere que se realicen varias reflexiones en cuanto a aspectos como la financiación de la innovación, las capacidades y las competencias para competir internacionalmente de las personas emprendedoras o la efectividad de los programas de apoyo para la innovación e internacionalización de las start-up españolas. Crear condiciones para que puedan surgir nuevas empresas innovadoras y globales puede contribuir a la mejora del bienestar social, transformar mercados, originar nuevos hábitos sociales y dar solución a problemas que afectan a los colectivos más necesitados de la población.

\section{BIBLIOGRAFÍA}

ACS, Z. J. (2006), "New firm formation and the region: empirical results from the United States", en Santarelli, E. (ed.), Entrepreneurship, Growth and innovation, Springer, pp. 105-133.

ACS, Z. J., SZERB, L. y AUTIO, E. (2015), "The global entrepreneurship and development index", Global Entrepreneurship and Development Index 2014, Springer International Publishing, pp. 39-64.

ALCALDE, H. y GUERRERO, M. (2014), "Open business models in entrepreneurial stages: evidence from young Spanish firms during expansionary 
and recessionary periods", International Entrepreneurship and Management Journal, vol. 12, núm. 2, pp. 393-413.

APARICIO, S., URBANO, D. y AUDRETSCH, D. (2016), "Institutional factors, opportunity entrepreneurship and Economic growth: Pane data evidence", Technological Forecasting and Social Change, vol. 102, pp. 45-61. ARDICHIVILI, A., CARDOZO, R. y RAY, S. (2003), "A theory of entrepreneurial opportunity identification and development", Journal of Business Venturing, vol. 18, núm. 1, pp. 105-123.

ARCHIDIVILI, A. y CARDOZO, R. N. (2000), "A model of entrepreneurial opportunity recognition process", Journal of Enterprising Culture, vol. 8, núm. 02, pp. 103-119.

AUDRETSCH, D. B. y THURIK, R. (2001), "Linking entrepreneurship to growth", OECD Science, Technology and Industry Working Papers, 2001/02.

AUDRETSCH, D. B. y FRITSCH, M. (1994), "The geography of firm births in Germany", Regional Studies, vol. 28, núm. 4, pp. 359-365.

DE LOS RIOS, S., RODRÍGUEZ, I. y SÁENZ-DÍEZ, R. (2015), "Emprendedores y capital riesgo en España: el caso de Fond-ICO Global”, Revista Icade. Revista de las Facultades de Derecho y Ciencias Económicas y Empresariales, núm. 94, pp. 31-65.

ESTRIN, S., KOROSTELEVA, J. y MICKIEWICZ, T. (2012), "Which institutions encourage entrepreneurial growth aspirations?", Journal of Business Venturing, vol. 28, núm. 4, pp. 564-580.

EVANS, E. y LEIGHTON, L. (1990), "Small business formation by unemployed and employed workers", Small Business Economics, vol. 2, núm. 4, pp. 319-330.

GEM (2013), Informe Global Entrepreneurship Monitor España 2013. Disponible en http://www.gem-spain.com/

GONZALEZ PERNIA, J. L., JUNG, A. y PEÑA, I. (2015), "Innovationdriven entrepreneurship in developing economies", Entrepreneurship and Regional Development, vol. 27, núm. 9-10, pp. 555-573.

HERRMANN, B., MARMER, M., DOGRULTAN, E. y HOLSTSCHKE, D. (2012), "Start-up ecosystem report 2012: PartOne", Start-up Genome and Telefonica Digital. Obtenida el 9 de enero de 2013, de http://reports. startupcompass.co/

HESSELS, J., VAN GELDEREN, M. y THURIK, R. (2008), "Entrepreneurial aspirations, motivations and their drivers", Small Business Economics, vol. 31, núm. 3, pp. 323-329.

MASON, C. y BROWN, R. (2014), "Entrepreneurial ecosystems and growth oriented entrepreneurship", Final Report to OECD, Paris.

SARASVATHY, S. D., DEW, N., VELAMURI, S. R. y VENKATARAMAN, S. (2010), "Three views of entrepreneurial opportunity", en Acs, Z. J. y 
Audretsch, D. B. (eds.), Handbook of Entrepreneurship Research, Springer, pp. 141-160.

SHANE, S. y VENKATARAMAN, S. (2000), "The promise of entrepreneurship as a field of research", Academy of Management Review, vol. 25 núm 1, pp. 217-226.

VECIANA, J. M. y URBANO, D. (2008), "The institutional approach to entrepreneurship research: introduction", International Entrepreneurship and Management Journal, vol. 4 núm.4, pp. 365-379.

WELTER, F. y SMALLBONE, D. (2011), "Institutional perspectives on entrepreneurial behaviour in challenging environments", Journal of Small Business Management, vol. 49, núm. 1, pp. 107-125. 